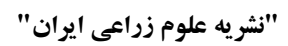

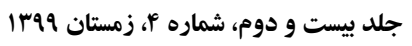

ارزيابى ساز كارى و يايدارى عملكرد دانه زنوتيبهاى منتخب كينوا (Chenopodium quinoa Willd)

در نظامهاى كشت بهاره در مناطق سرد و معتدل

Assessment of adaptability and seed yield stability of selected quinoa

(Chenopodium quinoa Willd.) genotypes in spring cropping systems in cold and temperate regions of Iran

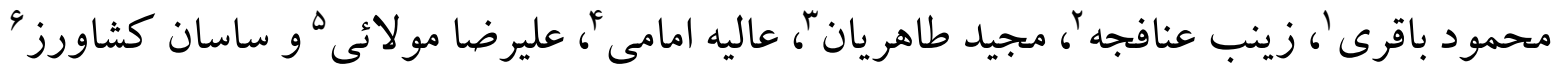
جكيده

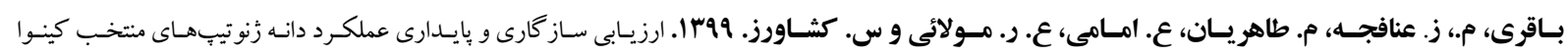
(Chenopodium quinoa Willd.)

اين تحقيق با هدف ارزيابى ساز كارى و پايدارى عملكرد دانه زنوتيبهاى كينوا در نظام كشت بهاره در منـاطق سـرد و معتـل

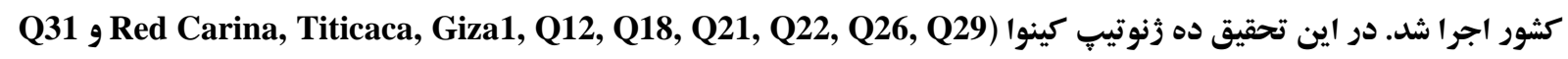

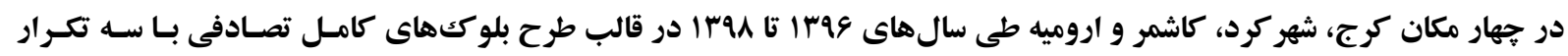

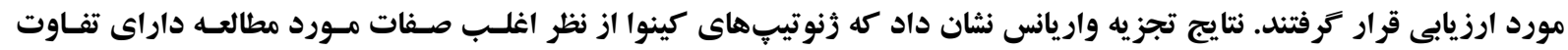

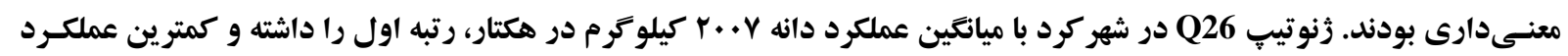

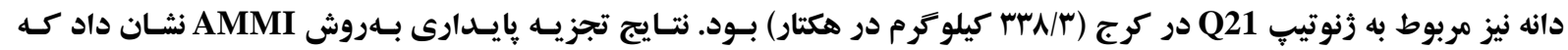

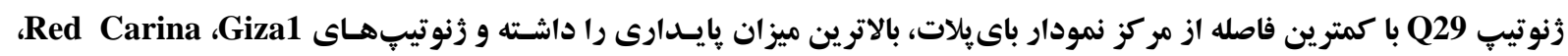

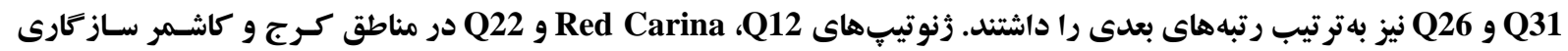

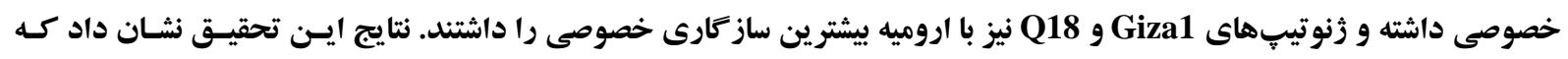
كليه زنوتيبهاى كينواى مورد ارزيابى براى كثت بهاره در مكانهاى اجراى آزمايش ساز

وازههاى كليدى: تجزيه AMMI، ساز كارى، عملكرد دانه، كينوا و مولفهاى اصلى.

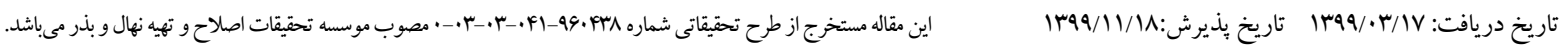
ا- استاديار موسسه تحقيقات اصلاح و تهيه نهال و بذر، سازمان تحقيقات آموزش و ترويج كثاورزى، كرج، ايران إنان (مكاتبه كنده)

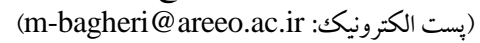

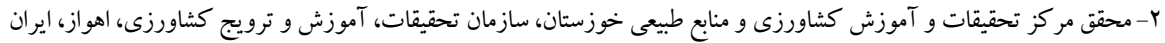

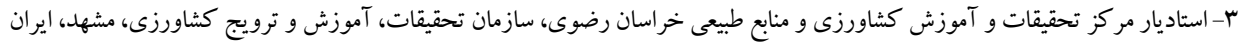

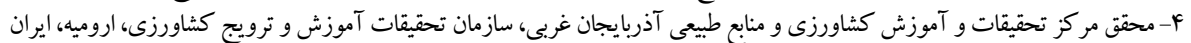

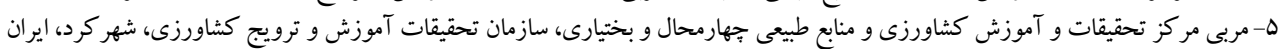

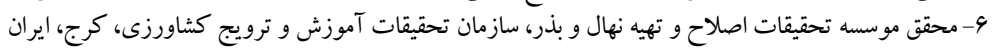


شهريور، به دليل نبود غذاى كافى براى برند كان در اين

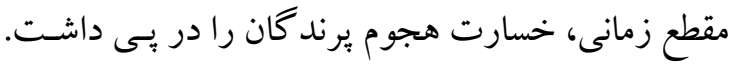

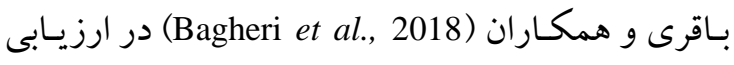

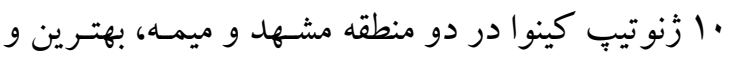

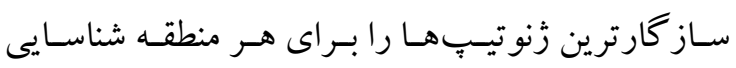
كردند. سـيهوند و همكـاران (Sepahvand et al., 2010)

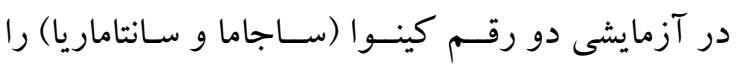

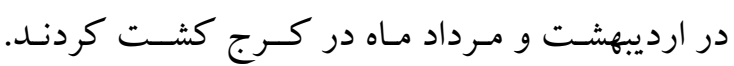
نتـايج نشـان داد كـه كاشـت در مـاه مـــرداد محصــول مناسب ترى توليد كرد، ولى در كاشت در ارديبهشت، باد داد

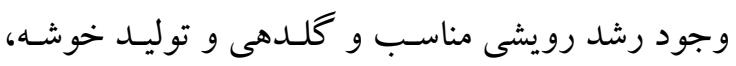

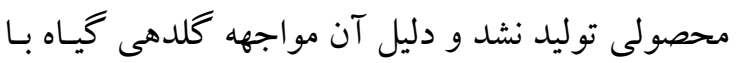

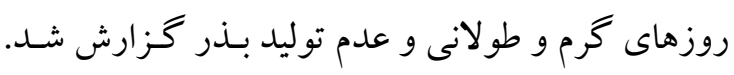

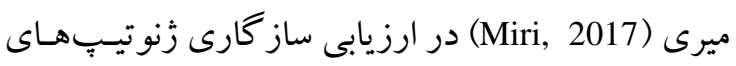

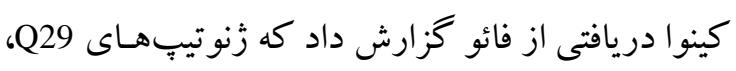

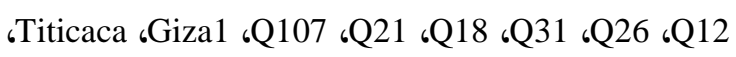

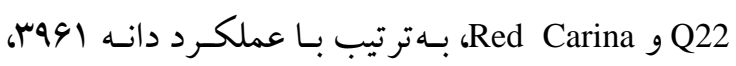
r.r. :

$$
\text { زُنو تيبّها بودند. }
$$

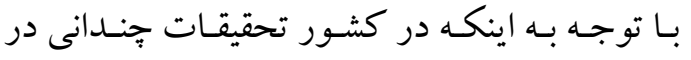

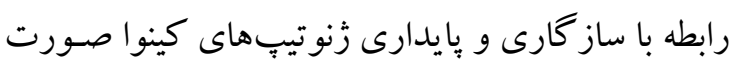

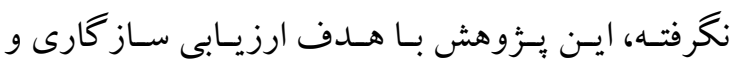

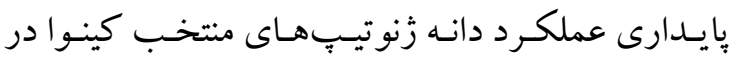

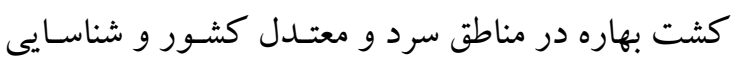

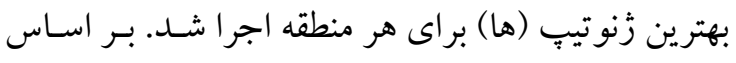

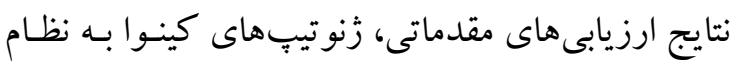

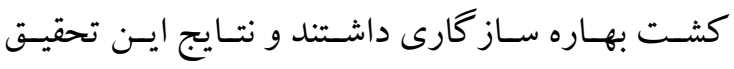

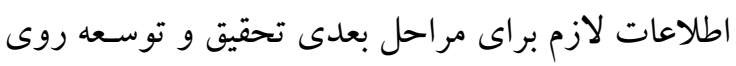

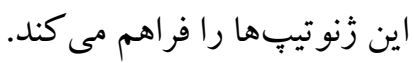

\section{مواد و روشها}

Red در اين تحقيق ده زنوتيب منتخب كينوا شـامل Carina, Titicaca, Giza1, Q12, Q18, Q21, Q22, Q26,

\section{مقدمه}

كينـوا (Chenopodium quinoa Willd. تساجخـروس (Amarahnthaceae) بـومى كينـوا يـك فيك

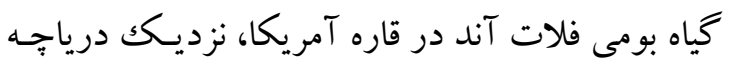

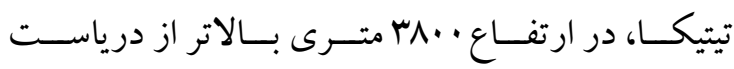

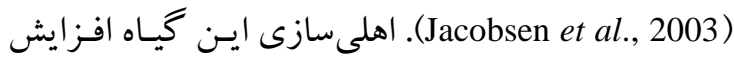

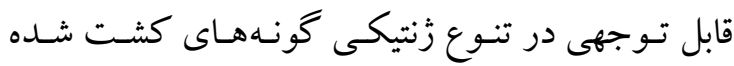

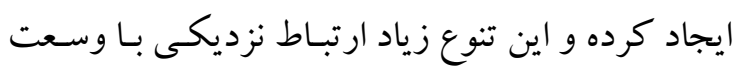

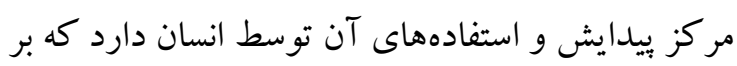

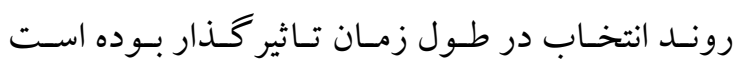
(Bhargava and Srivastava, 2013)

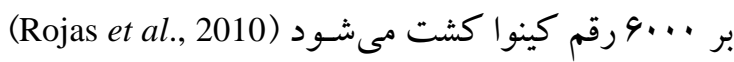

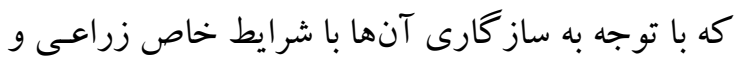

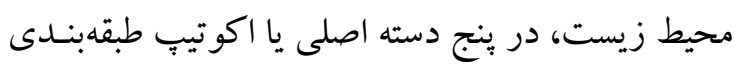
مىشوند (Bois et al., 2006; Fuentes et al., 2009).

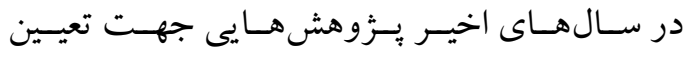

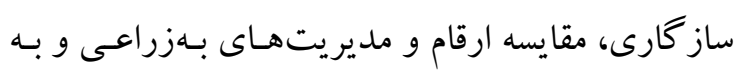

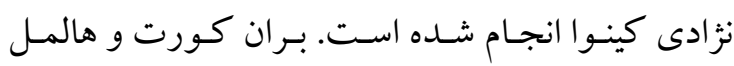
(Brancourt Hulmel et al., 2000) بـرهمكنش زنوتيـبِ در محيط دليـل اصليى تفـاوت در

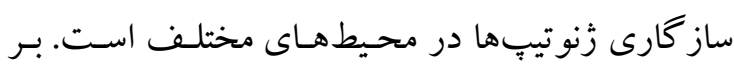

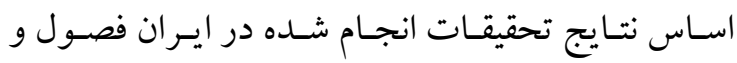
تاريخهاى كشت مختلفى براى كينو ا معرفى شده اسـت كشت بهاره در منـاطق سـرد و معتـدل، كشـت تابستانه

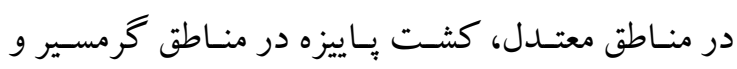

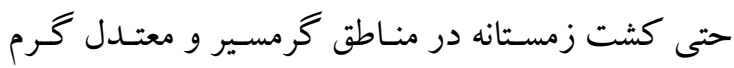

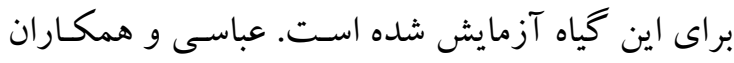

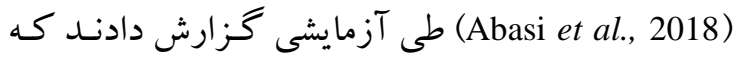

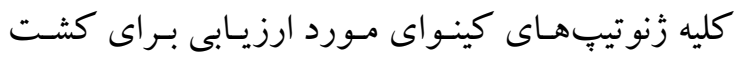

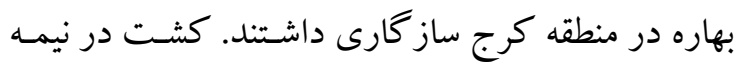

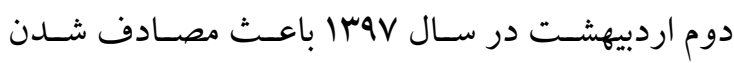

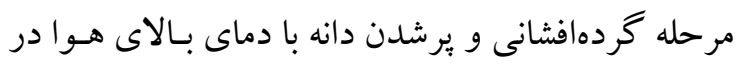

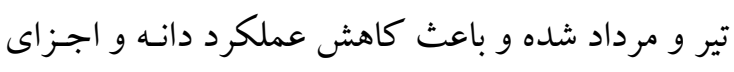

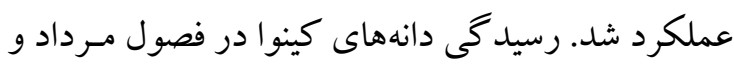


در هكتـار در سـه مرحلـه آمـادهسـازى زمسين، ·Y-Yها سانتى مترى بوتهها و شروع كلدهى به خاكك داده شدند.

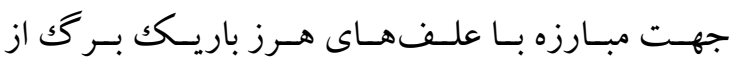
علف كش سوير كالانت استفاده شـد و علـف هـاى هـرز بهنبر گك با وجين دستى كنتـرل شـدند. صـفات گيـاهى

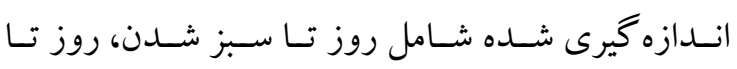
كـردهافشـانى، روز تـا رسـيدكى فيزيولوزيـك، ارتفـاع بوته، طول گحل آذيسن، عملكـرد دانسه، وزن هـز ار دانـه و محتواى سايونين دانه بودند. اندازه گيرى ميزان سـايونين دانسها بـر اسـاس دسـتور العمل توصـيف شــده توسـط كوزيول (Koziol, 1991) انجام شد. براى ايـن كـار يـنج كرم بذر خشك در لوله آزمايش به طول •19 ميلىمتـر و قطر 19 ميلى متر ريخته شده و به آن يـنج ميلى ليتـر آب اضافه شد. لولهها به مدت .ب ثانيه بـه شـدت تكـان داده

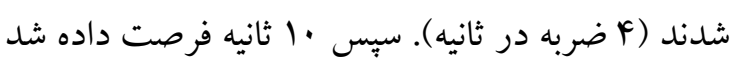

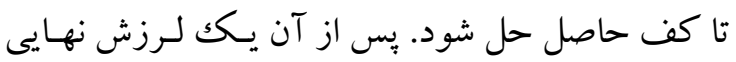
داده شده و ارتفاع كف از بالاى آب اندازه كيـرى شـد. ميزان سايونين بـه ازاى گحرم وزن تـر دانـه بـا اسـتفاده از رابطه يكك بر آورد شد (Koziol, 1991).
در قالب طرح بلو ككهاى كامـل تصـادفى در Q29, Q31 سه تكرار و در جهار منطقه كرج، شـهر كرد، كاشـمر و

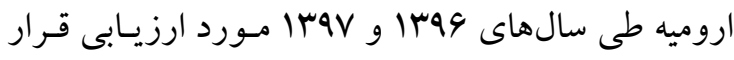
كرفتند. هر كرت آزمايشى شامل سه رديف كاشت ينج متـرى بـود. فاصـله رديف هــاى كاشـت .9 سـانتى متـر، فو اصل كاشت روى رديف 9 تا 1 سانتى متر، فاصله بـين

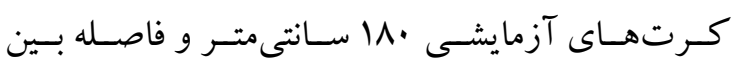

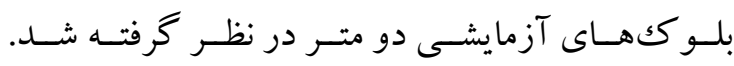

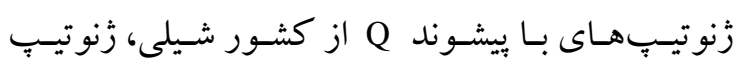
Titicaca هلند دريافت شدند. كاشـت بـــر در كاشـمر در اسـفند، در كـرج در ارديبهشت و در اروميه و شهر كرد در خرداد انجـام شـد. تهيه بستر كاشت همانند ساير بذور كياهان دانهريز شامل شخم، كودياشى، ديسكك و ايجـاد جـوى و بِشـته بـود.

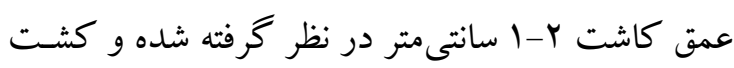
به صورت رديفى (جوى و بشــه) انجـام شـد. كودهـاى

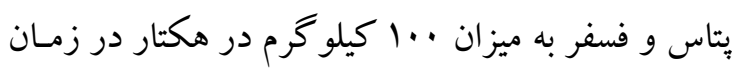

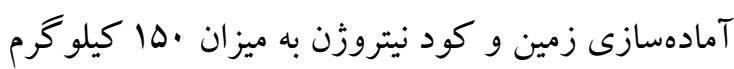

نبـود. نتـايج ايسـن آزمــايش در مــورد اكثـر صـفات مـورد ارزيسابى بـا نتـايج تحقيقـات بـاقرى و همكــاران (Bagheri et al., 2018) بــاقرى (Bagheri, 2019) عباسـى و همكــاران (Abasi et al., 2018)، ميـرى (2018) (Miri, 2017) و مولائى (Molaei, 2016) مطابقت دارد.

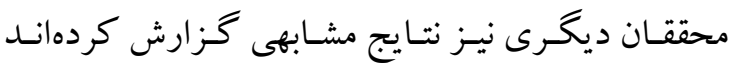
(Tan and Temel, 2018) بجز ميزان سايونين دانه معنى دار بـود. شـايد اصـلى تـرين دليل اين تفاوت مربـوط بـه شـرايط دمـايى متفـاوت در

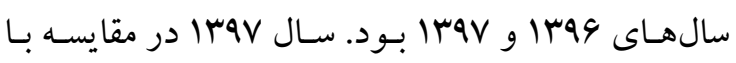
سال 941 و ميانگگين سالهاى قبل، گرمتر بود. عليـرغم

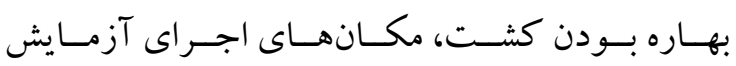

تجزيــه واريـانس و مقايسـات ميـانخين دادههــا بـا استفاده از آزمون حداقل اختلاف معنى دارى (LSD) بـا نرمافزار 9.3 و SAS ver مححاسـبـات تجزيـهـ يايـــدارى

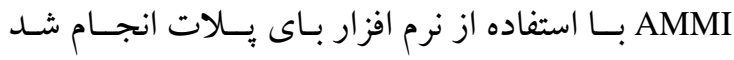

.(Yan et al., 2007)

\section{نتايج و بحث}

نتايج تجزيه واريانس مركب براى سالها و مكانهـا نشـان داد كـه زنوتيـبِهــاى كينـوا از نظـر اكثـر صـفات مـورد مطالعـه داراى اخـتلاف معنــى دارى بودنـــ، امـا بــرهمكنش زنوتيــب در مككـان در ســال بــر صــات ارتفاع بوته، طول گل آذين و روز تا گـل دهـى معنى دار 
زُنوتيبهاى كينوا به كشت بهاره در منـاطق مـورد نظر

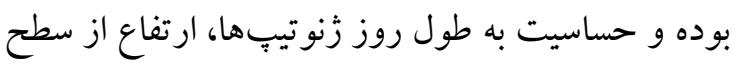

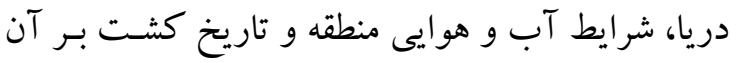

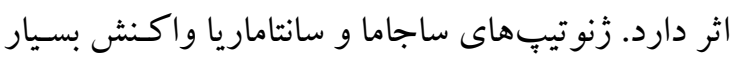
جدى به روز كوتاهى داشته و فقط در شرايط روز كو تاه

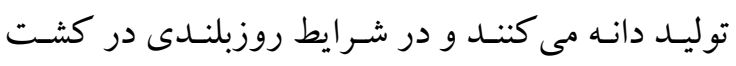

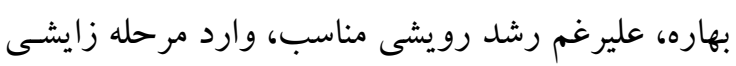

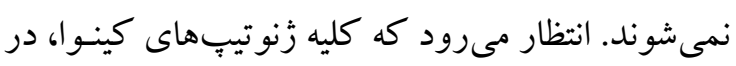
كشت تابستانه توليد محصول دانه داشته باشند، ليكن در درو

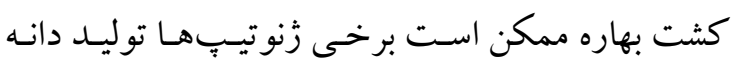

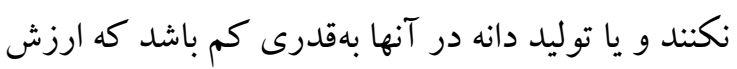

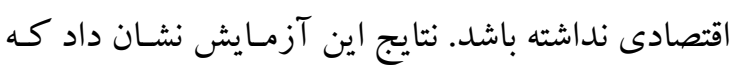

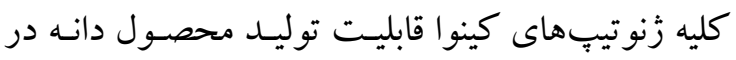
شـرايط روزبلنـدى كشـت بهـاره را داشـتند و بنـابراين

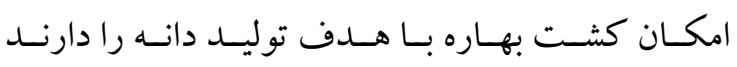

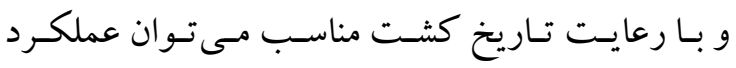

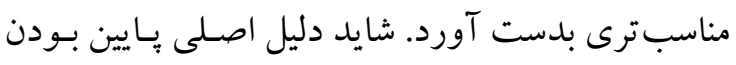

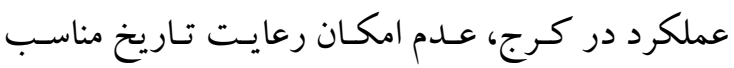
كاشت بود و در صورت كاشـت بـــر در زمـان مناسـب (بهمن تا اسفند) احتمال دستيابى بـه عملكر دهـاى بـالاتر وجـود دارد. عباسى و همكار ان (Abbasi et al., 2018)

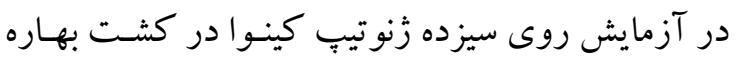

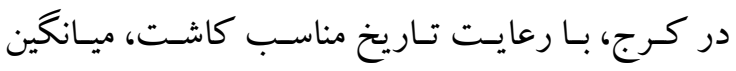

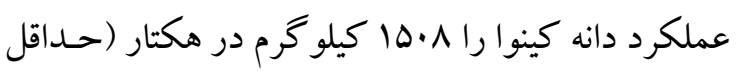

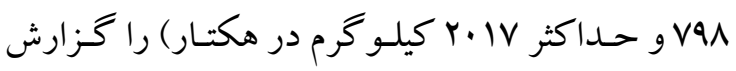
كردند. دليل ديخر پايين بودن عملكرد دانه به خصـوص

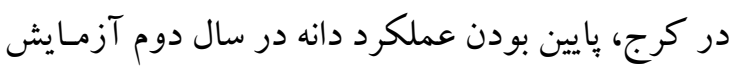

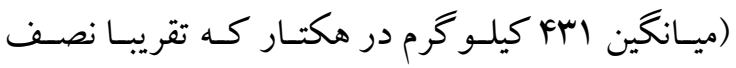

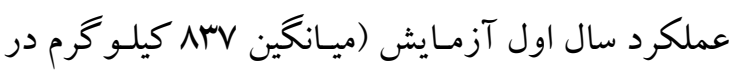
هكتار) بود كه دليل آن گرمـاى بـالاى هـوا در تابستئان

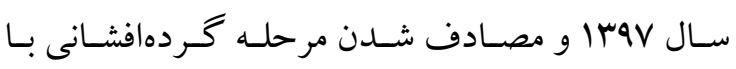

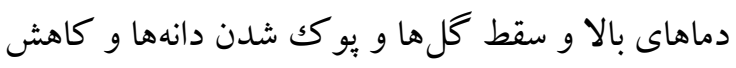
عملكرد دانه بود.

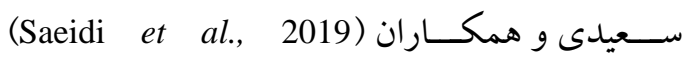

تفاوتهاى اقليمى واضحى داشـتند كـه باعـث معنى دار شدن اثر مكان براى كليه صفات مورد مطالعه شد. كرج

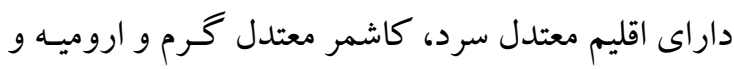

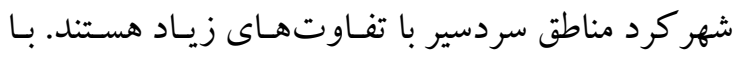

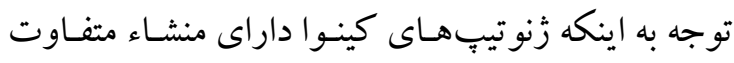

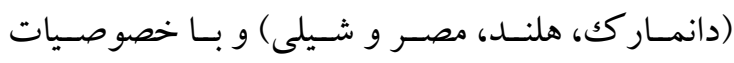

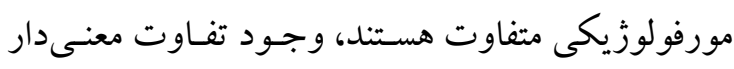
در صفات آنها قابل انتظسار بـود. نتـايج تحقيقـات انجـام شده توسط باقرى (Bagheri, 2019)، عباسى و همكاران

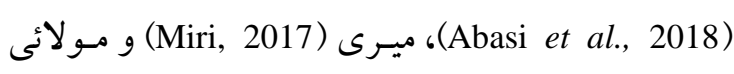

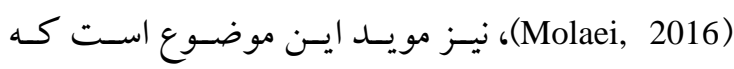

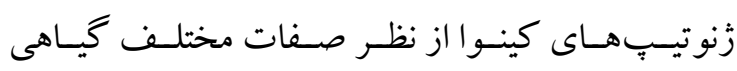
تفاوت هاى معنى دارى داشتند.

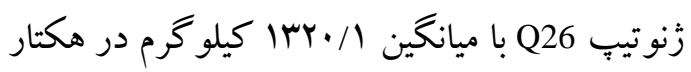
داراى بيشترين عملكرد دانه بود. نتايج آزمايش مـوليَ لائى (Molaei, 2016)

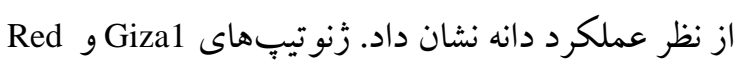
ن29 و نarina Titicaca

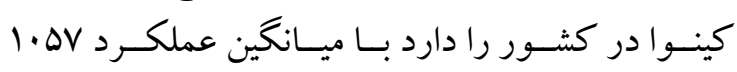
كيلو گرم در هكتار رتبه ينجم راد داشت. بر اسـاس نتسايج

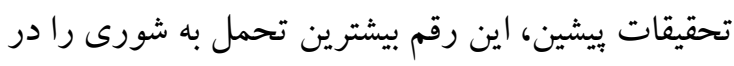

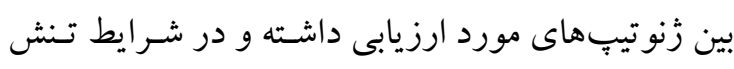

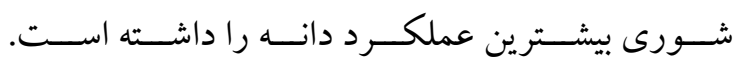

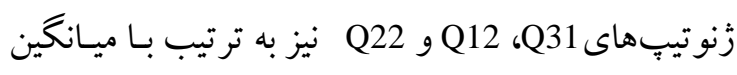

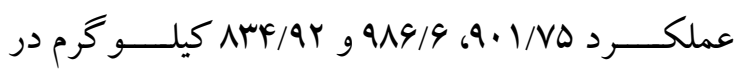

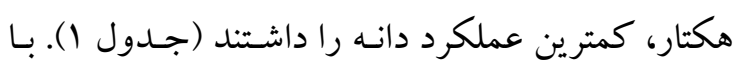
توجـه بـه تجـارب قبلى در مـورد فصـل كشـت، تـاريخ

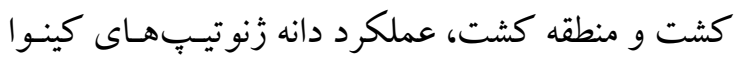
در اثر مصادف شدن مرحله كردهافشانى و برشـدن دانسه

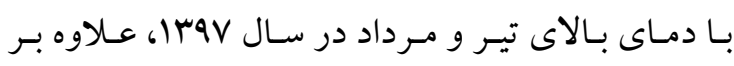
كاهش تعداد دانهاى تشكيل شده، باعـث كـاهش وزن

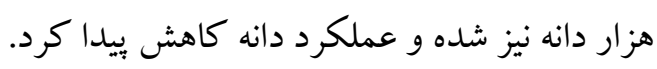

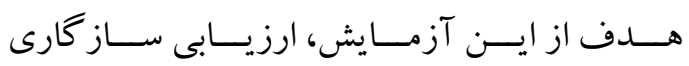


(Abasi et al., 2018; Bagheri et al., 2018)

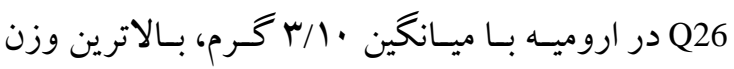

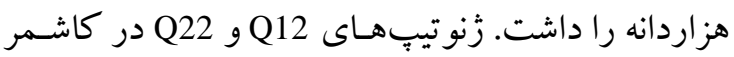

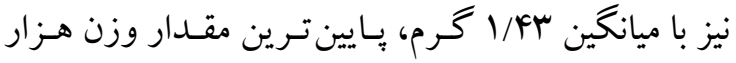
دانه را داشتند (جدول r) (ب).

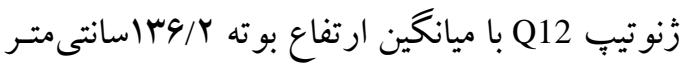

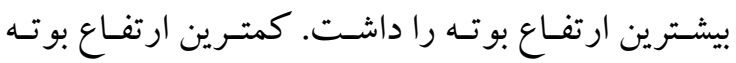

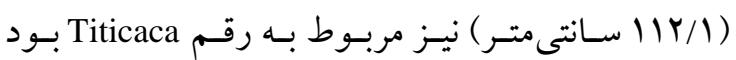

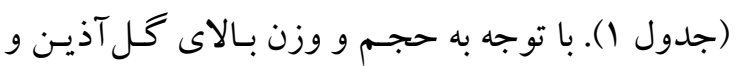

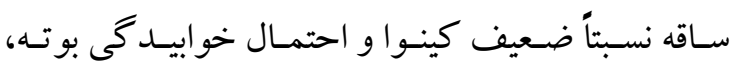

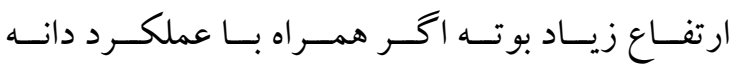
مناسب نباشد، صفت مطلوبى نخو اهد بود. با اين وجـود رود

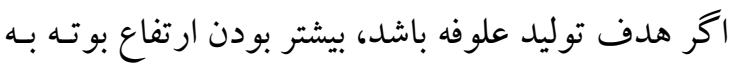

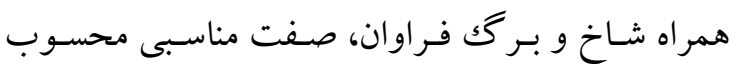

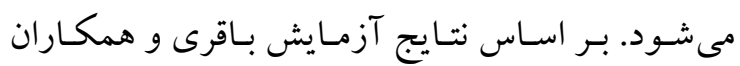
كينواى زنوتيـب (Bagheri et al., 2018) ميمه اصفهان، بيشترين ارتفاع بوته را داشت كه بـا نتايج

$$
\text { تحقيق حاضر تطابق دارد. }
$$

ويز گى تعداد روز تـا گـردهافشـانى در كينـوا عامـل

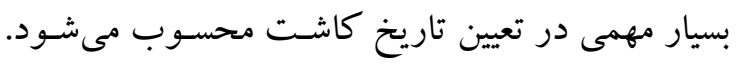

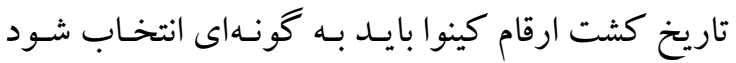

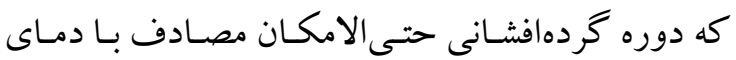

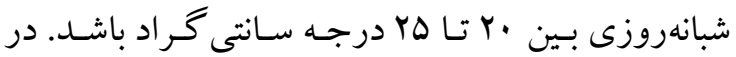

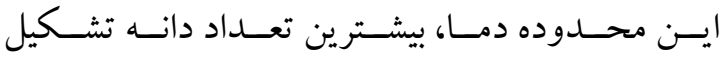

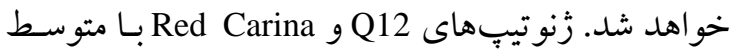
ك/r/ و و /

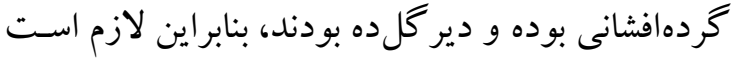

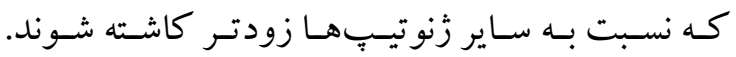

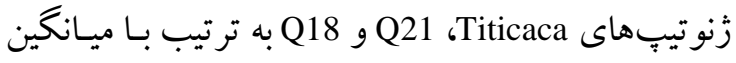

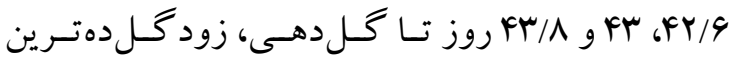

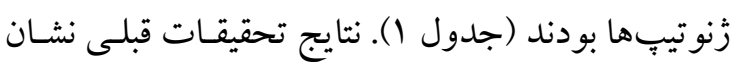

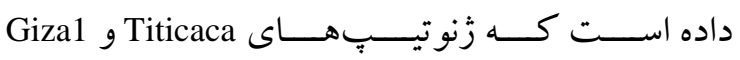

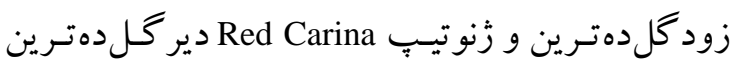
بودند (Bagheri, 2019; Molaei, 2016).

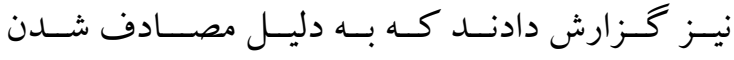

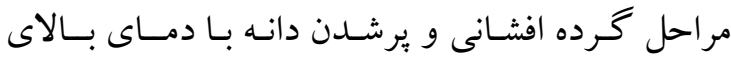

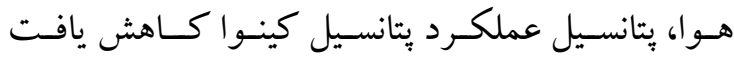

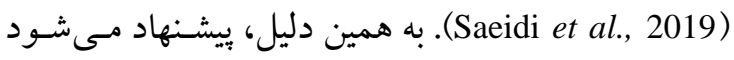

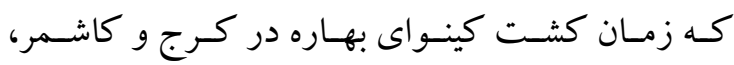
از ارديبهشت و خـرداد بـهـ اسفند و بهمسن و در اروميسه

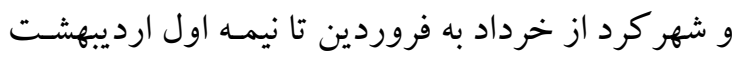

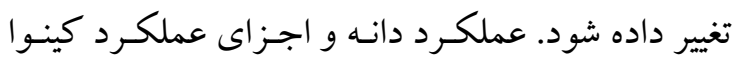

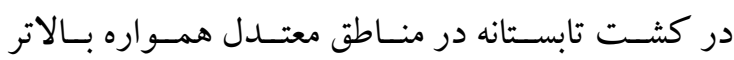

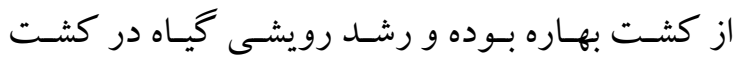

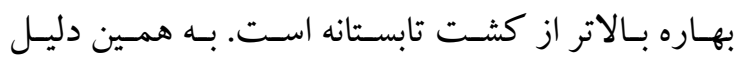

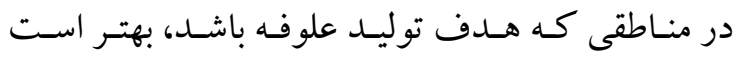

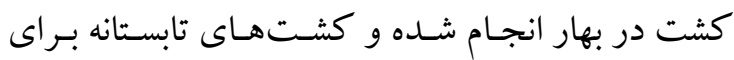

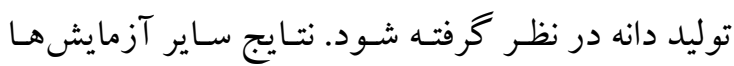

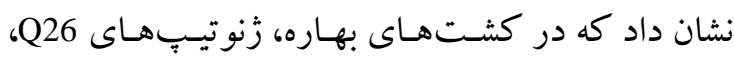
Red Carina و Gizal ،Q29 .(Abasi et al., 2018; Bagheri, 2019; Bagheri et al., 2018)

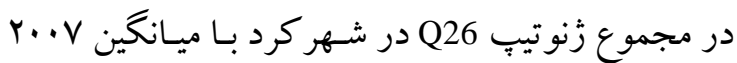

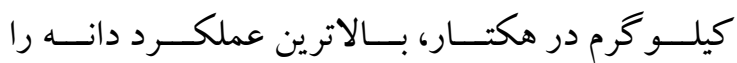

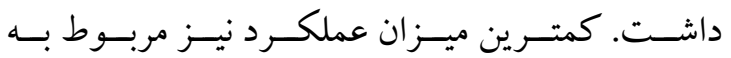

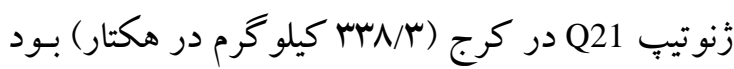

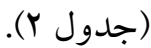

رنو تيّب Q26 بالاترين مقدار وزن هزار دانه را داشت ( F/VN)

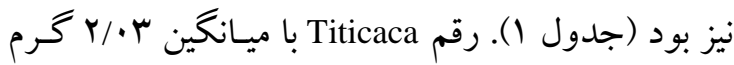
كمترين وزن هزار دانه را داشـت. عليـرغم خصوص صـيات

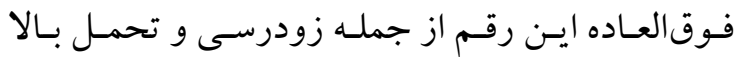

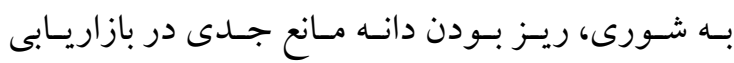
و صادرات آن است. ميانگين وزن هزاردانه كينوا ب تا 9

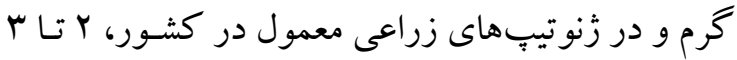

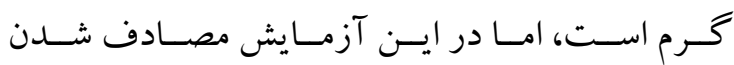

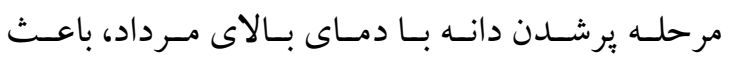

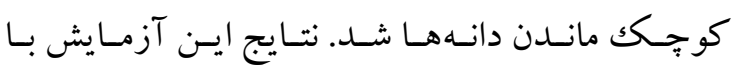

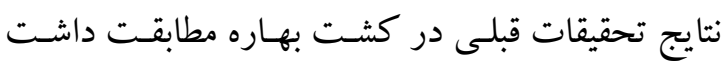




\section{"نشريه علوم زراعى ايران"، جلد بيست و دوم، شماره F، زمستان 9ج\|}

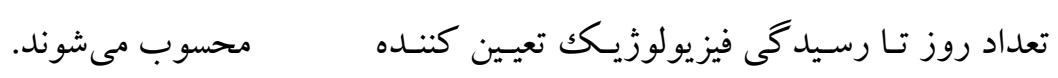

همانطور كه در جدول Y مشاهده مىشـود، محتو اي

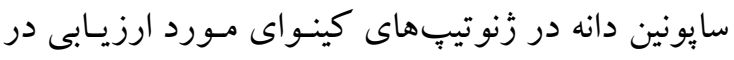

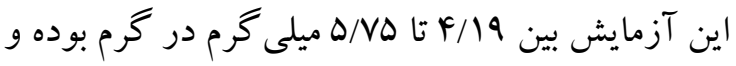

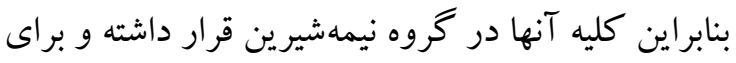

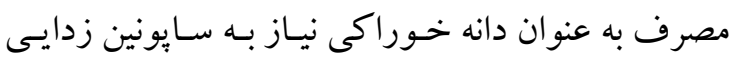

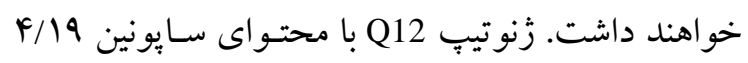

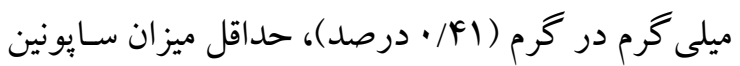

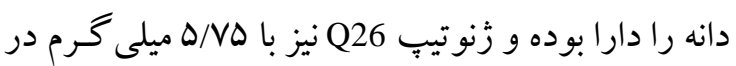

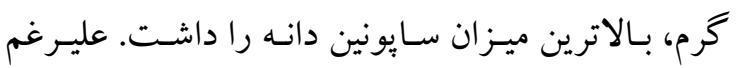

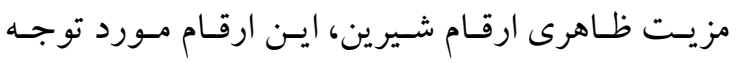

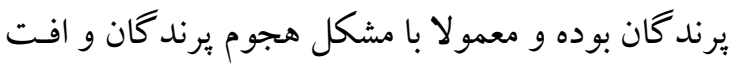
بالاى محصول مو اجه هستند. وجـود سـايونين در دانـهـا

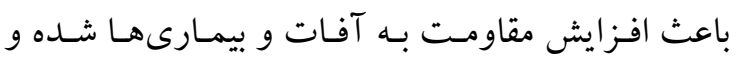
بنابراين عليرغم ايجاد تلخـى، داراى مزايسايى نيـز اسـتـ

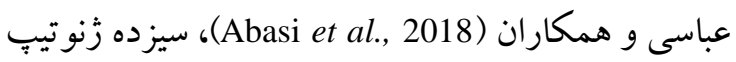

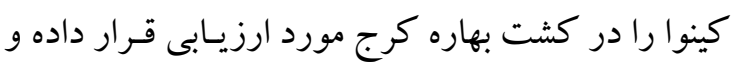

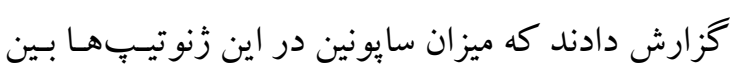

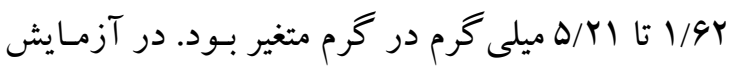

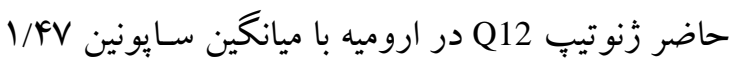

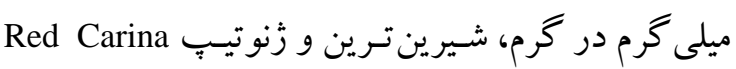

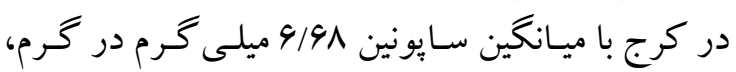

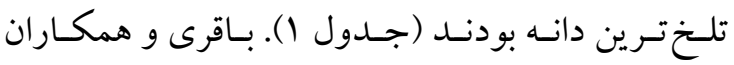
نيـز در ارزيـابى زنو تيسِّهـاى (Bagheri et al., 2018)

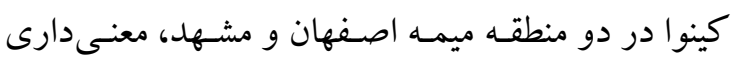

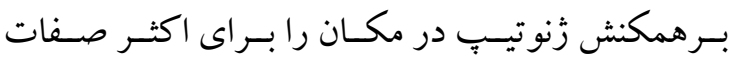

$$
\text { كزارش كردند. }
$$

نتايج تجزيههاى بايدارى به روش AMMI و نمـودار

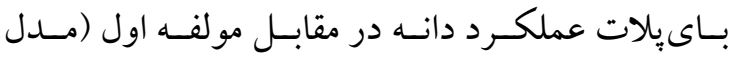

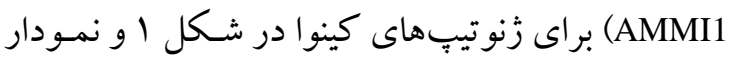

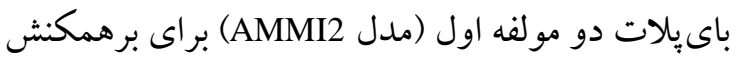

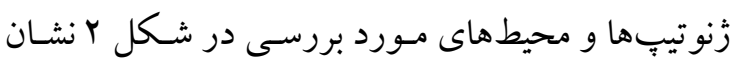

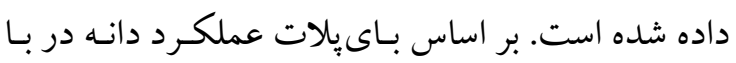

زودرسى و ديررسى ارقام اسـت. زنوتيـِّهـاى زودرس

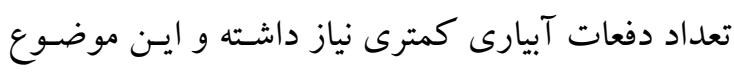

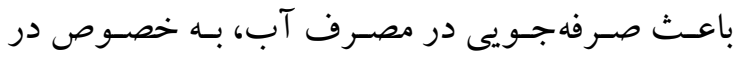

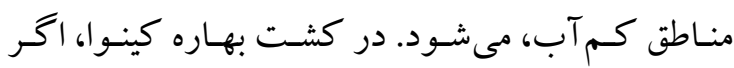
هدف كشت دوم بعد از برداشت كينوا باشد، اين امكـان در ارقام زودرس تر قابل حصـولتــ اسـت. از ايـن نظـر،

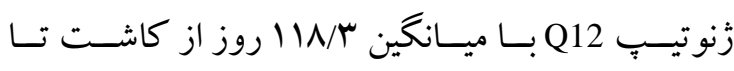

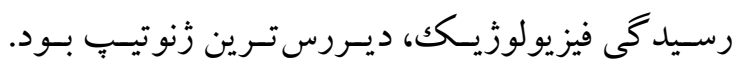

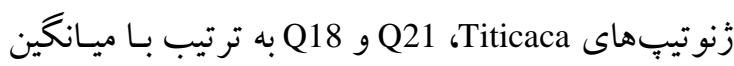

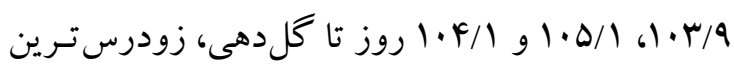

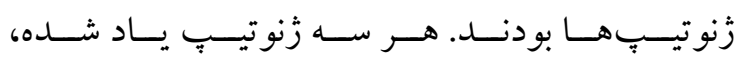

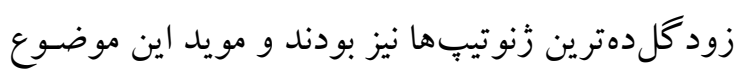

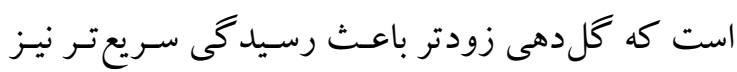

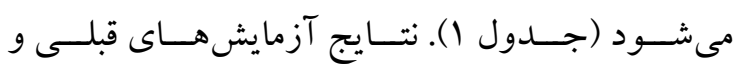

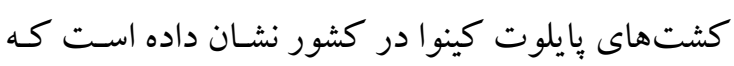

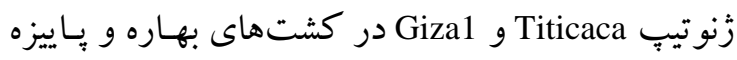

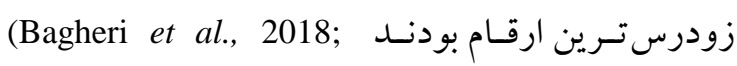
Sepahvand, 2013; Tavoosi and Sepahvand, 2012) زنوتيـبـهـاى Q29، Q31 و Q12 در اروميـه بـا ميـانكخين

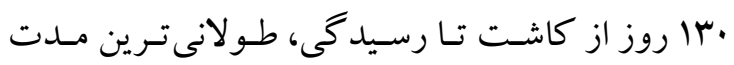

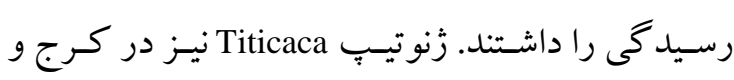

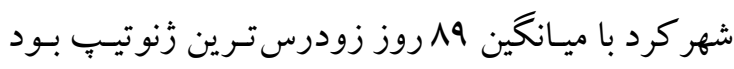

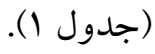
بين زنو تيبٍ هاى كينوا از نظر محتـواى سـايونين دانـه

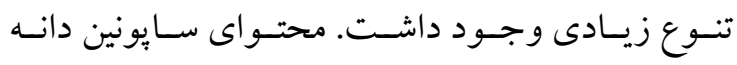

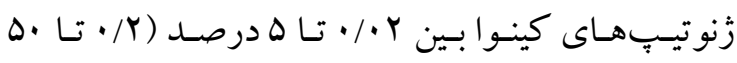

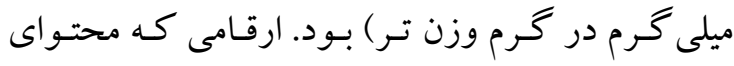

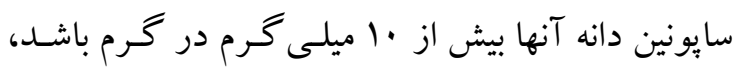

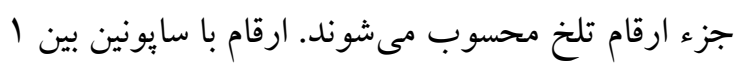

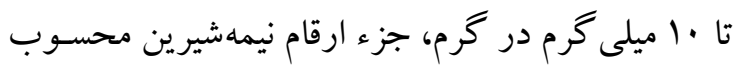

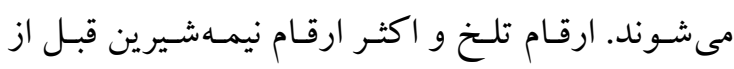
مصرف، نياز به سايونين زدايى دارنســ ارقـام بـا سـايونين

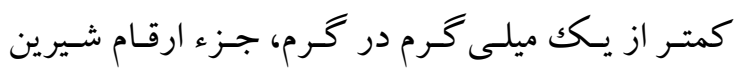


جدول (- ميانكين صفات گياهى زنو تيبهاى كينوا (ميانگين جهار مكان)

Table 1. Mean of plant traits of quinoa genotypes (mean of four locations)

\begin{tabular}{|c|c|c|c|c|c|c|c|c|}
\hline $\begin{array}{c}\text { زنوتيبهاى كينواى } \\
\text { Quinoa genotypes }\end{array}$ & $\begin{array}{c}\text { روز تا سبز شدن } \\
\text { Days to emergence }\end{array}$ & $\begin{array}{c}\text { روز تا كلدهى } \\
\text { Days to flowering } \\
\end{array}$ & $\begin{array}{c}\text { روز تا رسيدگى } \\
\text { Days to physiological maturity }\end{array}$ & $\begin{array}{c}\text { ارتفاع بوته } \\
\text { Plant height } \\
\text { (cm) }\end{array}$ & $\begin{array}{c}\text { طول كل آذين } \\
\text { Inflorescence length } \\
(\mathrm{cm})\end{array}$ & $\begin{array}{c}\text { عملكرد دانه } \\
\text { Seed yield } \\
\left(\mathrm{kg} \cdot \mathrm{ha}^{-1}\right) \\
\end{array}$ & $\begin{array}{c}\text { وزن هزاردانه } \\
1000 \text { seed weight } \\
\text { (g) }\end{array}$ & $\begin{array}{c}\text { سايونين دانه } \\
\text { Saponin content } \\
\left(\mathrm{mg} \cdot \mathrm{g}^{-1}\right)\end{array}$ \\
\hline Red Carina & $4.4 \mathrm{ab}$ & $53.0 \mathrm{a}$ & $115.5 \mathrm{ab}$ & $131.4 \mathrm{abc}$ & $33.2 \mathrm{a}$ & $1188.4 \mathrm{ab}$ & $2.42 \mathrm{abc}$ & $5.25 \mathrm{ab}$ \\
\hline Titicaca & $4.3 \mathrm{ab}$ & $42.5 \mathrm{e}$ & $103.9 \mathrm{~d}$ & $112.0 \mathrm{c}$ & $31.0 \mathrm{ab}$ & $1057.0 \mathrm{ab}$ & $2.03 \mathrm{c}$ & $5.71 \mathrm{bc}$ \\
\hline Giza1 & $4.8 \mathrm{ab}$ & $46.9 \mathrm{~cd}$ & $108.5 \mathrm{bcd}$ & $115.5 b c$ & $32.1 \mathrm{a}$ & $1226.1 \mathrm{ab}$ & $2.51 \mathrm{ab}$ & $5.98 \mathrm{abc}$ \\
\hline Q12 & $5.1 \mathrm{a}$ & $53.2 \mathrm{a}$ & $118.2 \mathrm{a}$ & $136.2 \mathrm{a}$ & $28.8 \mathrm{bc}$ & $986.6 \mathrm{ab}$ & $2.47 \mathrm{abc}$ & $5.19 \mathrm{c}$ \\
\hline Q18 & $4.8 \mathrm{ab}$ & $43.7 \mathrm{de}$ & $104.0 \mathrm{~cd}$ & $119.1 \mathrm{abc}$ & $33.5 \mathrm{a}$ & $1154.6 \mathrm{ab}$ & $2.62 \mathrm{a}$ & $5.32 \mathrm{ab}$ \\
\hline Q21 & $4.2 \mathrm{~b}$ & $42.7 \mathrm{e}$ & $105.0 \mathrm{~cd}$ & $124.7 \mathrm{abc}$ & $25.2 \mathrm{~d}$ & $1037.6 \mathrm{ab}$ & $2.58 \mathrm{ab}$ & $5.32 \mathrm{ab}$ \\
\hline Q22 & $4.6 \mathrm{ab}$ & $51.5 \mathrm{ab}$ & $112.8 \mathrm{abc}$ & $121.2 \mathrm{abc}$ & $24.5 \mathrm{~d}$ & $834.9 \mathrm{~b}$ & $2.51 \mathrm{ab}$ & $5.34 \mathrm{ab}$ \\
\hline Q26 & $4.6 \mathrm{ab}$ & $51.7 \mathrm{ab}$ & $108.1 \mathrm{bcd}$ & $132.1 \mathrm{ab}$ & $31.9 \mathrm{a}$ & $1320.0 \mathrm{a}$ & $2.78 \mathrm{a}$ & $5.76 \mathrm{a}$ \\
\hline Q29 & $4.7 \mathrm{ab}$ & $51.0 \mathrm{ab}$ & 111.0abcd & $128.4 \mathrm{abc}$ & $28.0 \mathrm{c}$ & $1173.5 \mathrm{ab}$ & $2.63 \mathrm{a}$ & $5.10 a b c$ \\
\hline Q31 & $4.6 \mathrm{ab}$ & $49.1 \mathrm{bc}$ & $115.0 \mathrm{ab}$ & $118.2 \mathrm{abc}$ & $26.7 \mathrm{~cd}$ & $901.7 \mathrm{ab}$ & $2.15 b c$ & $5.17 \mathrm{abc}$ \\
\hline
\end{tabular}

Means in each column followed by similar letter(s) are not significantly different at 5\% probability level, using LSD test 


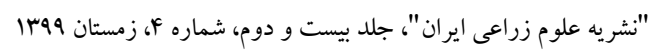

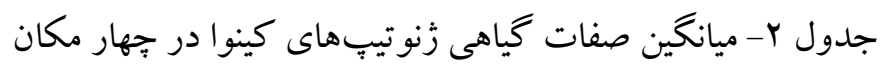

Table 2. Mean of plant traits of quinoa genotypes in four locations

\begin{tabular}{|c|c|c|c|c|c|c|c|c|c|c|}
\hline $\begin{array}{c}\text { Location } \\
\text { Lotion } \\
\end{array}$ & & $\begin{array}{c}\text { زُنوتيبهاى كينوا } \\
\text { Quinoa genotypes } \\
\end{array}$ & $\begin{array}{c}\text { روز تا سبز شدن } 2 \text { رays to emergence } \\
\end{array}$ & $\begin{array}{c}\text { روز تا كلدهى } \\
\text { Days to flowering } \\
\end{array}$ & 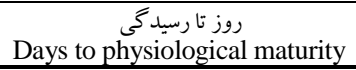 & $\begin{array}{c}\text { ارتفاع بوته } \\
\text { Plant height (cm) } \\
\end{array}$ & 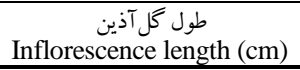 & $\begin{array}{c}\text { ع عملكرد دانه } \\
\text { Seed yield }\left(\mathrm{kg}^{\left.-\mathrm{ha}^{-1}\right)}\right. \\
\end{array}$ & $\begin{array}{c}\text { وزن هزار دانه } 1000 \text { seed weight (g) } \\
\end{array}$ & $\begin{array}{c}\text { سايونين انه } \\
\text { Saponin content (mg.g }{ }^{-1} \text { ) }\end{array}$ \\
\hline Karaj & كرج & Red Carina & $4.6 \mathrm{def}$ & $54.6 \mathrm{abc}$ & $110.6 \mathrm{hi}$ & $178.3 \mathrm{a}$ & $37.3 \mathrm{a}$ & $800.01 \mathrm{~m}$ & $2.87 \mathrm{defg}$ & $6.6 \mathrm{a}$ \\
\hline Karaj & كرج & Titicaca & 4.0fgh & $40.3 \mathrm{~m}$ & $89.0 \mathrm{r}$ & $136.5 \mathrm{def}$ & $34.3 \mathrm{bc}$ & $710.0 \mathrm{mn}$ & $2.08 \mathrm{i}$ & $5.8 \mathrm{~cd}$ \\
\hline Karaj & كرج & Giza1 & $4.0 \mathrm{fgh}$ & $45.3 \mathrm{ijk}$ & 98.3op & $147.0 \mathrm{~cd}$ & $37.3 \mathrm{a}$ & 618.3 no & $2.90 \mathrm{defg}$ & $6.6 \mathrm{a}$ \\
\hline Karaj & كرج & Q12 & $5.3 \mathrm{~cd}$ & $55.6 \mathrm{ab}$ & $112.0 \mathrm{ghi}$ & $162.5 \mathrm{~b}$ & $31.0 \mathrm{fg}$ & 602.5 nop & 2.98abcdef & $5.7 \mathrm{de}$ \\
\hline Karaj & كرج & Q18 & $5.3 \mathrm{~cd}$ & $43.0 \mathrm{kl}$ & $96 \mathrm{p}$ & $146.6 \mathrm{~cd}$ & $37.3 \mathrm{a}$ & $517.5 \mathrm{opq}$ & 3.00abcde & $5.9 \mathrm{bcd}$ \\
\hline Karaj & كرج & Q21 & 4.0fgh & $40.6 \mathrm{ml}$ & $91.6 \mathrm{qr}$ & $146.0 \mathrm{~cd}$ & 27.0jklmn & $338.3 \mathrm{~s}$ & $2.85 \mathrm{efg}$ & $6.2 \mathrm{abc}$ \\
\hline Karaj & كرج & Q22 & $4.6 \mathrm{def}$ & $56.3 \mathrm{a}$ & $109.0 \mathrm{ij}$ & $147.1 \mathrm{~cd}$ & 26.6jklmn & $361.6 \mathrm{sr}$ & $2.83 \mathrm{fg}$ & $5.6 \mathrm{de}$ \\
\hline Karaj & كرج & Q26 & 4.0fgh & $53.0 \mathrm{cdef}$ & $103.6 \mathrm{~lm}$ & $149.0 \mathrm{c}$ & $35.0 \mathrm{~b}$ & $1023.3 \mathrm{k}$ & $3.08 \mathrm{ab}$ & $6.5 \mathrm{a}$ \\
\hline Karaj & كرج & Q29 & $3.6 \mathrm{gh}$ & $54.3 \mathrm{abc}$ & 99.3 no & $147.1 \mathrm{~cd}$ & 29.6ghi & 854.11 & $3.02 \mathrm{abcd}$ & $6.4 \mathrm{a}$ \\
\hline Karaj & كرجبا & Q31 & 4.3efg & $52.6 \mathrm{cdef}$ & $104.6 \mathrm{klm}$ & $116.1 \mathrm{i}$ & 28.0ijkl & $516.6 \mathrm{opq}$ & $2.08 \mathrm{i}$ & $6.6 \mathrm{a}$ \\
\hline Kashmar & كاشمر & Red Carina & 4.3efg & $53.3 \mathrm{bcde}$ & $120.0 \mathrm{~cd}$ & 138.6cdef & $35.3 \mathrm{ab}$ & $789.31 \mathrm{~m}$ & $1.67 \mathrm{kl}$ & $6.4 \mathrm{a}$ \\
\hline Kashmar & كاشمر & Titicaca & $3.6 \mathrm{gh}$ & $40.3 \mathrm{~m}$ & 114.0fg & $129.8 \mathrm{fgh}$ & 31.6efg & $846 \cdot 1$ & $1.77 \mathrm{jk}$ & $5.1 \mathrm{fg}$ \\
\hline Kashmar & كاشمر & Giza1 & $3.6 \mathrm{gh}$ & 46.6hij & 116.0ef & 131.5efg & $33.6 \mathrm{bcde}$ & $793.61 \mathrm{~m}$ & $1.60 \mathrm{~lm}$ & $5.6 \mathrm{de}$ \\
\hline Kashmar & كاشمر & Q12 & $4.0 \mathrm{fgh}$ & $54.3 \mathrm{abc}$ & $120.0 \mathrm{~cd}$ & $142.1 \mathrm{cde}$ & $28.3 \mathrm{ijk}$ & $616.3 \mathrm{no}$ & $1.43 n$ & 4.6hi \\
\hline Kashmar & كاشمر & Q18 & $5.0 \mathrm{de}$ & $41.01 \mathrm{~m}$ & $123.0 \mathrm{bc}$ & 129.0fgh & $34.3 \mathrm{bc}$ & $486.1 \mathrm{pq}$ & $1.70 \mathrm{kl}$ & $5.0 \mathrm{gh}$ \\
\hline Kashmar & كاشمر & Q21 & 4.0fgh & $40.0 \mathrm{~m}$ & 116.3ef & 131.6efg & 26.3klmno & $468.0 \mathrm{qr}$ & $1.50 \mathrm{mn}$ & $4.9 \mathrm{gh}$ \\
\hline Kashmar & كاشمر & Q22 & $3.3 \mathrm{~h}$ & $54.3 \mathrm{abc}$ & 117.6de & $129.0 \mathrm{fgh}$ & 26.01mno & 487.3pq & $1.43 n$ & $4.4 \mathrm{i}$ \\
\hline Kashmar & كاشمر & Q26 & 4.3efg & $50.6 \mathrm{fg}$ & 119.0de & 135.6def & $33.3 \mathrm{bcde}$ & $714.6 \mathrm{mn}$ & $1.87 \mathrm{j}$ & $5.6 \mathrm{de}$ \\
\hline Kashmar & كاشمر & Q29 & 4.3efg & $54.3 \mathrm{abc}$ & $118.3 \mathrm{de}$ & $139.5 \mathrm{cdef}$ & 27.3jklm & $643.0 \mathrm{n}$ & $1.67 \mathrm{kl}$ & $5.5 \mathrm{def}$ \\
\hline Kashmar & كاشمر & Q31 & $3.3 \mathrm{~h}$ & 51.0efg & 117.0def & 133.0efg & 26.6jklmn & 411.6qrs & $1.50 \mathrm{mn}$ & $6.3 \mathrm{ab}$ \\
\hline Shahrekord 2 & شهركر & Red Carina & $5.0 \mathrm{de}$ & $51.6 \mathrm{def}$ & $107.3 \mathrm{jk}$ & 121.7ghi & $28.3 \mathrm{ijk}$ & 1698.0de & 2.90defg & 5.6de \\
\hline Shahrekord 2 & شهركر & Titicaca & $5.0 \mathrm{de}$ & $48.0 \mathrm{~h}$ & $89.3 \mathrm{r}$ & $100.0 \mathrm{jk}$ & 26.3klmno & $1243.3 \mathrm{j}$ & $2.08 \mathrm{i}$ & $5.6 \mathrm{de}$ \\
\hline Shahrekord 2 & شهركر & Giza1 & 6.6ab & 51.0efg & $102.0 \mathrm{mn}$ & $100.0 \mathrm{jk}$ & 27.0jklmn & $1745.3 \mathrm{~cd}$ & 2.93bcdefg & $5.1 \mathrm{fg}$ \\
\hline Shahrekord 2 & شهركر & Q12 & $7.0 \mathrm{a}$ & $52.3 \mathrm{cdef}$ & 110.3hij & $141.8 \mathrm{cde}$ & $25.0 \mathrm{no}$ & $1432.6 \mathrm{gh}$ & $2.85 \mathrm{efg}$ & $4.9 \mathrm{gh}$ \\
\hline Shahrekord 2 & شهركر & Q18 & $5.3 \mathrm{~cd}$ & 49.0gh & 92.0rq & $118.8 \mathrm{hi}$ & 28.6hij & $1798.6 \mathrm{~cd}$ & 2.97abcdef & $5.9 \mathrm{bcd}$ \\
\hline Shahrekord 2 & شهركر & Q21 & $5.3 \mathrm{~cd}$ & $50.0 \mathrm{gh}$ & $92.6 q^{\circ}$ & 132.3efg & $20.3 q$ & $1854.1 \mathrm{bc}$ & $2.92 \mathrm{cdefg}$ & $4.5 \mathrm{hj}$ \\
\hline Shahrekord 2 & شهركر & Q22 & $6.0 \mathrm{bc}$ & 54.0abcd & 112.0ghi & $122.3 \mathrm{ghi}$ & $20.0 \mathrm{q}$ & $1400.1 \mathrm{hi}$ & $2.80 \mathrm{~g}$ & $5.9 \mathrm{bcd}$ \\
\hline Shahrekord & شهركر & Q26 & $5.3 \mathrm{~cd}$ & $55.6 \mathrm{ab}$ & $105.3 \mathrm{kl}$ & $140.2 \mathrm{cdef}$ & 27.0jklmn & $2007.0 \mathrm{a}$ & $3.07 \mathrm{abc}$ & $5.9 \mathrm{bcd}$ \\
\hline Shahrekord 2 & شهركر & Q29 & $6.0 \mathrm{bc}$ & $54.6 \mathrm{abc}$ & $97.0 \mathrm{op}$ & 130.6efgh & $24.3 \mathrm{op}$ & $1967.8 \mathrm{ab}$ & 2.98abcdef & $4.9 \mathrm{gh}$ \\
\hline Shahrekord 2 & شهركر & Q31 & $6.33 \mathrm{ab}$ & 53.0cdef & $109.0 \mathrm{ij}$ & $132.5 \mathrm{efg}$ & $22.6 \mathrm{p}$ & $1583.8 \mathrm{ef}$ & $2.12 \mathrm{i}$ & $3.9 \mathrm{j}$ \\
\hline Urmia & اروميه & Red Carina & 4.6def & $52.6 \mathrm{cdef}$ & $124.0 \mathrm{~b}$ & $87.01 \mathrm{~m}$ & $32.0 \mathrm{def}$ & $1466.3 \mathrm{gh}$ & $2.23 \mathrm{i}$ & $2.2 \mathrm{k}$ \\
\hline Urmia & اروميه & Titicaca & 4.6def & $41.61 \mathrm{~m}$ & $123.3 b$ & $82.0 \mathrm{~m}$ & 31.6efg & $1429.0 \mathrm{gh}$ & $2.20 \mathrm{i}$ & $2.2 \mathrm{k}$ \\
\hline Urmia & اروميه & Giza1 & $5.0 \mathrm{de}$ & $41.6 \mathrm{~lm}$ & $117.6 \mathrm{de}$ & $83.5 \mathrm{~m}$ & $30.6 \mathrm{fgh}$ & $1747.1 \mathrm{~cd}$ & $2.60 \mathrm{~h}$ & $2.5 \mathrm{k}$ \\
\hline Urmia & اروميه & Q12 & 4.3efg & $50.6 \mathrm{fg}$ & $130.6 \mathrm{a}$ & $98.33 \mathrm{jkl}$ & $31.0 \mathrm{fg}$ & $1295.0 \mathrm{ij}$ & $2.60 \mathrm{~h}$ & 1.41 \\
\hline Urmia & اروميه & Q18 & $3.6 \mathrm{gh}$ & $42.01 \mathrm{~m}$ & $105.3 \mathrm{kl}$ & $82 \mathrm{~m}$ & $34.0 \mathrm{bcd}$ & $1816.1 \mathrm{c}$ & $2.80 \mathrm{~g}$ & $4.4 \mathrm{i}$ \\
\hline Urmia & اروميه & Q21 & $3.6 \mathrm{gh}$ & $41.31 \mathrm{~m}$ & $119.6 \mathrm{~d}$ & $89.1 \mathrm{klm}$ & $27.3 \mathrm{jklm}$ & $1490.1 \mathrm{fgh}$ & $3.07 \mathrm{abc}$ & $5.5 \mathrm{def}$ \\
\hline Urmia & اروميه & Q22 & 4.6def & $41.61 \mathrm{~m}$ & $112.6 \mathrm{gh}$ & $86.51 \mathrm{~m}$ & $25.3 \mathrm{mno}$ & $1090.5 \mathrm{k}$ & 2.97abcdef & $5.3 \mathrm{efg}$ \\
\hline Urmia & اروميه & Q26 & $5.0 \mathrm{de}$ & 47.6hi & $104.6 \mathrm{klm}$ & $103.8 \mathrm{j}$ & $32.3 \mathrm{cdef}$ & $1535.3 \mathrm{fg}$ & $3.10 \mathrm{a}$ & $4.9 \mathrm{gh}$ \\
\hline Urmia & اروميه & Q29 & $5.0 \mathrm{de}$ & $41.01 \mathrm{~m}$ & $129.6 \mathrm{a}$ & $96.6 \mathrm{jkl}$ & $30.6 \mathrm{fgh}$ & $1229.3 \mathrm{j}$ & $2.87 \mathrm{defg}$ & $3.5 \mathrm{j}$ \\
\hline Urmia & اروميه & Q31 & 4.6def & $40.0 \mathrm{~m}$ & $129.6 \mathrm{a}$ & $91.3 \mathrm{klm}$ & $29.6 \mathrm{ghi}$ & $1094.8 \mathrm{k}$ & $2.90 \mathrm{defg}$ & $3.8 \mathrm{j}$ \\
\hline
\end{tabular}




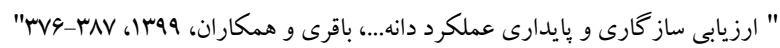

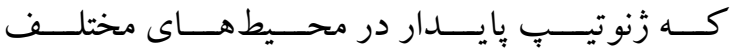

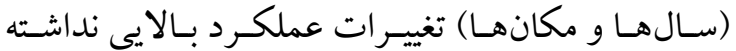

و عملكـرد نسـبتا ثـابتى داشـته و بـرهمكنش عملكــرد و

محيط براى آن زنوتيـٍ بـايين بـوده اسـت. در صسورتى

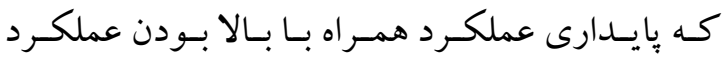

باشد، مطلوب بوده و انتخاب آن براى بهنزادگر آسـان
مقابـل مولفـه اول (مـدل AMMI1)، زنوتيـيّ 9 (Q29) كمترين فاصله از مركز نمودار، بايدارترين زنوتيب بود.

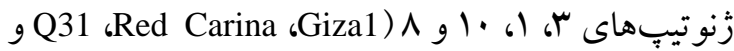
نيز به ترتيب بـا كمتـرين فاصـله از مركـز نمـودار (Q26

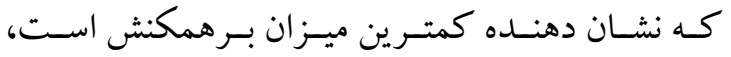

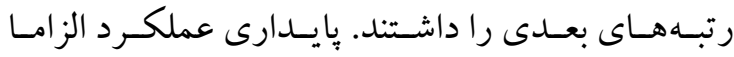
به معناى عملكرد بالا نيست، بلكه نشاندهنده اين اسـت

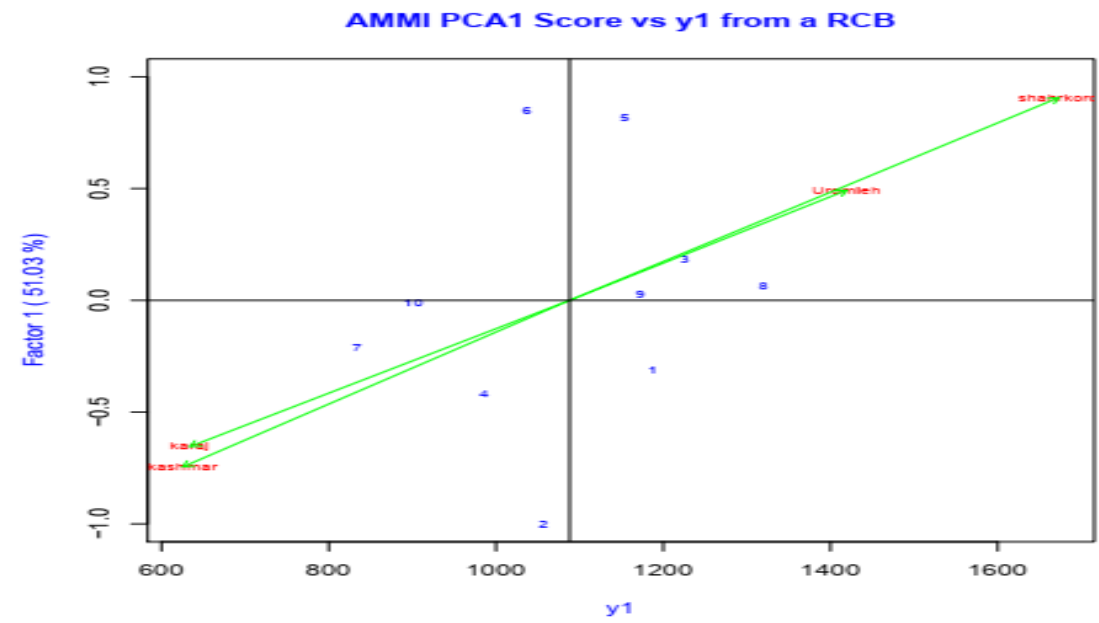

شكل ا - باى پِات عملكرد دانه در مقابل مولفه اول مدل AMMI1 براى زنوتيبٍ هاى كينوا

Fig. 1. Biplot of seed yield against the first component of AMMI1 model for quinoa genotypes

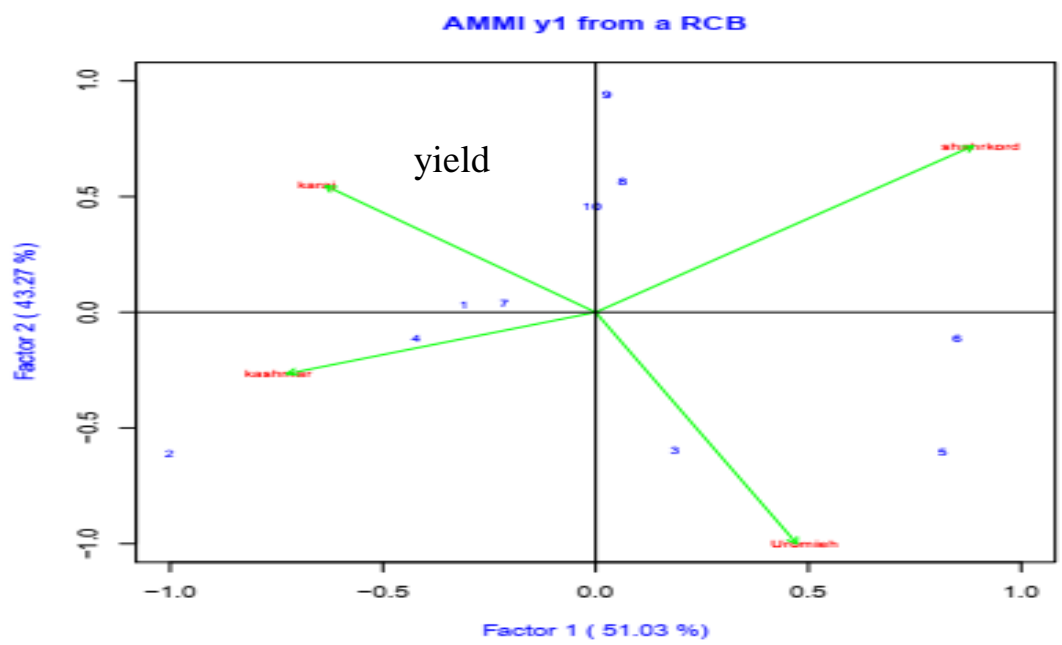

شكل Y- باى بِلات مدل AMMI2 دو مولفه اول بر ای برهمكنش زنوتيبٍ هاى كينوا و مكانهاى آزمايش

Fig. 2. Biplot of AMMI2 model for the interaction of quinoa genotypes and experiment locations 


\section{نتيجه كيرى}

نتايج ايـن تحقيـق نشـان داد كـه كليـه زنوتيـبـهـاى

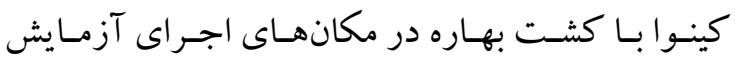

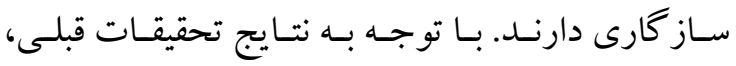

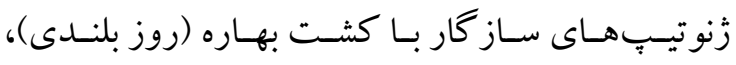
معمـولا در تابستان و يـاييز نيـز قابـل كشـت بـوده و بــه احتمال زياد در كليه فصول و مناطق كشور قابـل كشـت خو اهند بود. در حالى كه حالت عكس قطعيـت نـدارد،

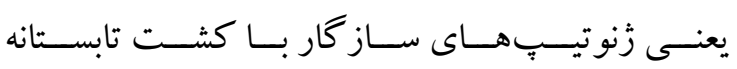
(روز كوتاهى) ممكن است در كشـت بهـاره توليـد دانسه نداشـته باشـند. كشـت در نيمسه دوم اردبيهشـت در سـال

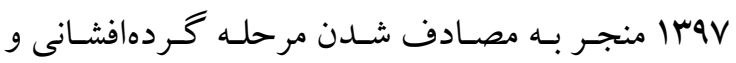
برشدن دانه با دماى بالاى هوا در تير و مـرداد شــده و بـا كاهش اجزاي عملكـرد (تعـداد دانسه و وزن هـزار دانسه) باعث كاهش عملكرد دانـه شـد. بعـلاوه طـولانى شــدن رسيدكى دانههاى كينوا تا فصسول مـرداد و شـهريور، بـهـ دليل نبود سـاير محصـولات دانـهاى، خسـارت ناشسى از هجوم يرند كان را در يسى خواهـد داشـت. بنـابراين بهتـر است كه كشت بهاره كينـوا در اولين فرصست ممكن و حتى به صورت كشت انتظارى در بهمن و اسـفند انجـام شود.

$$
\begin{aligned}
& \text { به منظور بررسى سـاز كارى خصوصى زنوتيسِ } \\
& \text { بــا مكــانهــاى آزمــايش از مــدل AMMI2 كـــه از } \\
& \text { يـالات كـردن دو مولفـهـ اصـلى اول ايجــاد مسىشـود، } \\
& \text { استفاده شد. در اين باىبلات كرج و كاشـمر بـه عنـوان }
\end{aligned}
$$

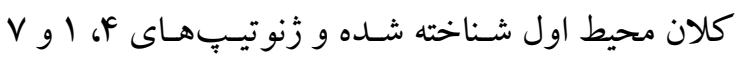

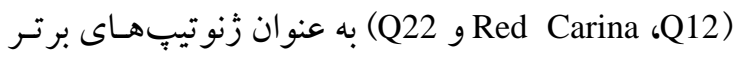

$$
\begin{aligned}
& \text { براى اين كلان محيط شـناخته شـدند. بـه عبـارت ديخـر }
\end{aligned}
$$

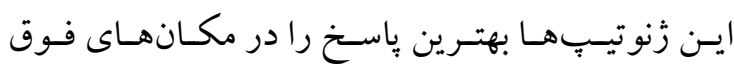

$$
\begin{aligned}
& \text { داشته و بـا ايسن مكـانهـا سـاز گارى خصو صسى داشـتند. }
\end{aligned}
$$

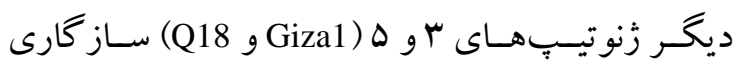

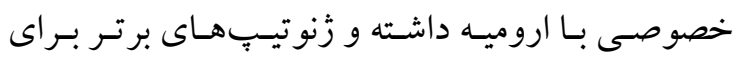

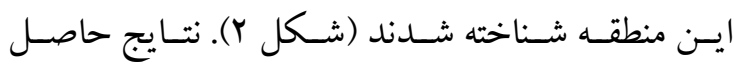

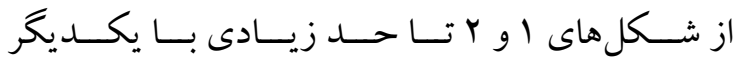

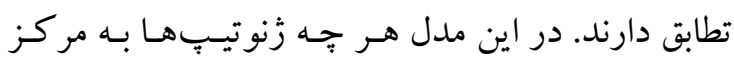

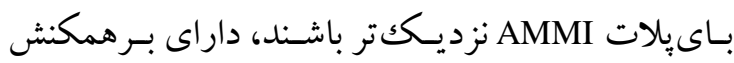

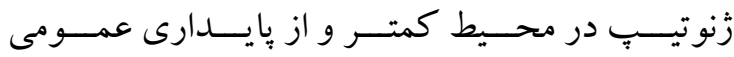

$$
\begin{aligned}
& \text { بيشترى برخوردار بوده و بنـابر اين بـراى اكثر مكـانهـا }
\end{aligned}
$$

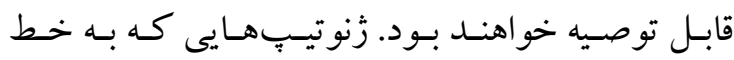

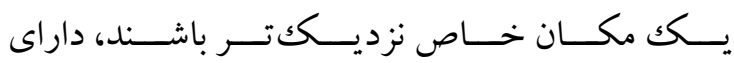

$$
\begin{aligned}
& \text { سـاز كارى خصوصى بــا آن منطقـه يـا منــاطق هسـتند }
\end{aligned}
$$

\section{References}

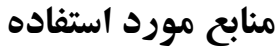

Abasi, S., A. Cordnaeich and M. Bagheri. 2018. Evaluation of genetic diversity of new chenopodium quinoa (Chenopodium quinoa Willd) cultivars based on agromorphological traits. $15^{\text {th }}$ National Iranian Congress Science Congress, 2-5 Sep. 2019. Karaj, Iran. (In Persian with English abstract).

Bagheri, M. 2019. Evaluation of quantitative and qualitative characteristics in new genotypes of quinoa (Chenopodium quinoa Willd.). Final Research Project Report, Agricultural Research and Information Center, Registration No. 55778. (In Persian with English abstract).

Bagheri, M., M.R. Zamani, H. Shouride, A.R. Molaei, A.R. Mansourian and F. Heydari. 2018. Evaluation of compatibility of quinoa genotypes in Mashhad and Isfahan. Final Research Project Report, Agricultural Research and Information Center, Registration No. 53795. (In Persian with English abstract).

Bhargava, A. and S. Srivastava. 2013. Quinoa Botany, Production and Uses. CABI.

Bois, J.F., T. Winkel, J.P., Lhomme, J.P. Raffaillac and A. Rocheteau. 2006. Response of some Andean cultivars of quinoa (Chenopodium quinoa Willd.) to temperature: effects on germination, phenology, growth 


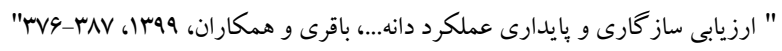

and freezing. Europ. J. Agron. 25: 299-308.

Brancourt Hulmel, M., B. Denis and C. Lecomte. 2000. Determining environmental covariates which explain genotype environment interaction in winter wheat through probe genotypes and biadditive factorial regression. Theor. Appl. Genet. 100: 285-298.

Fuentes, F., J. Maughan and E. Jellen. 2009. Diversidad genética y recursos genéticos para el mejoramiento de la quinoa (Chenopodium quinoa Willd.). Revista Geográfica de Valparaiso ํㅜ 42/2009. ISSN 0716 - 1905.

Gauch, H.G. and R.W. Zobel. 1997. Identifying mega-envitonments and targeting genotypes. Crop Sci. 31: 311-326.

Jacobsen, S.E., A. Mujicab and C.R. Jensenc. 2003. The resistance of quinoa (Chenopodium quinoa Wild.) to adverse abiotic factors. Food Rev. Int. 19(1-2): 99-109

Koziol, M.J. 1991. Afrosimetric estimation of threshold saponin concentration for bitterness in quinoa (Chenopodium quinoa Willd). J. Sci. Food Agric. 54: 211-219.

Miri, Kh. 2017. Evaluation of compatibility of quinoa genotypes to Iranshahr region. Final Report of the Research Project. Baluchestan Agriculture and Natural Resources Research and Training Center, Iranshahr, Iran. Agricultural Research and Extension Research Organization. (In Persian with English abstract).

Molaei, A. 2016. Evaluation of adaptation and response of some quinoa cultivars to day length in Shahrekord. Final Report of the Research Project. Chaharmahal \& Bakhtiari Province Agricultural and Natural Resources Research and Training Center. Agricultural Research and Extension Research Organization. (In Persian with English abstract).

Rojas-Beltran, J., A. Bonifacio, G. Botani and J. Maugham. 2010. Obtención de nuevas variedades de quinua frente a los efectos del cambio climático. Informe Compendio 2007-2010. Fundación PROINPA. Cochabamba, Bolivia.

Saeidi, S.M., S. A. Siadat, A. Moshatati, M.R. Moradi-Telavat and N.A. Sepahvand. 2020. Effect of sowing time and nitrogen fertilizer rates on growth, seed yield and nitrogen use efficiency of quinoa (Chenopodium quinoa Willd) in Ahvaz, Iran. Iran. J. Crop Sci. 21(4): 354-367. (In Persian with English abstract).

Sepahvand, N.A., M. Tavazoa and M. Kohbazi. 2010. Quinoa valuable plant for alimentary security and adaptation agricultural in Iran. $11^{\text {th }}$ National Iranian Crop Science Congress. 24-26 Jul. 2010. Tehran, Iran. (In Persian with English abstract).

Tan, M. and S. Temel. 2018. Performance of some quinoa (Chenopodium quinoa Willd.) genotype grown in different climate conditions. Turk. J. Field Crops. 23 (2):180-186.

Tavoosi, M. and N.A. Sepahvand. 2012. Evaluation of different genotypes of quinoa for yield and other phenological characteristics in khuzestan. $12^{\text {th }}$ Iranian Genetic Congress. 21-23 May, 2012. Shahid Beheshti University, Tehran, Iran. (In Persian with English abstract).

Yan, W., M.S. Kang, B. Ma, S. Woods and P.L. Cornelius. 2007. GGE biplot vs. AMMI analysis of genotype-by- environment data. Crop Sci. J. 47: 643-655. 


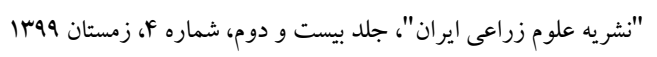

\title{
Assessment of adaptability and seed yield stability of selected quinoa (Chenopodium quinoa Willd.) genotypes in spring cropping systems in cold and temperate regions of Iran
}

\author{
Bagheri, M.1, Z. Anafjeh" ${ }^{2}$ M. Taherian ${ }^{3}$, A. Emami ${ }^{4}$, A.R. Molaie ${ }^{5}$ and S. \\ Keshavarz $^{6}$
}

\begin{abstract}
Bagheri, M., Z. Anafjeh, M. Taherian, A. Emami, A. R. Molaie and S. Keshavarz. 2021. Assessment of adaptability and seed yield stability of selected quinoa (Chenopodium quinoa Willd.) genotypes in spring cropping systems in cold and temperate regions of Iran. Iranian Journal of Crop Sciences. 22(4): 376-387. (In Persian).

To study the adaptability and seed yield stability, in this experiment, ten quinoa genotypes including; Red Carina, Titicaca, Giza1, Q12, Q18, Q21, Q22, Q26, Q29, Q29 and Q31 were evaluated using randomized complete block design with three replications in 2017 and 2018 in four locations; Karaj, Shahr-e-Kord, Kashmar and Urmia for their adaptability and grain yield stability. The results showed that quinoa genotypes had significant differences for most of the studied traits. However, genotype $\times$ location $\times$ year interaction effects on plant height, inflorescence length and days to flowering was not significant. Q26 genotype had the highest grain yield (2007 kg.ha ${ }^{-1}$ ) in Shahr-e-Kord. The lowest yield (338.33 kg.ha-1) was related to Q21 genotype in Karaj. The results of AMMI stability analysis showed that Q29 genotype had the highedt grain yiled stability with the shortest distance from the center of the graph. Cv. Giza1, cv. Red Carina, Q31 and Q26 genotypes also ranked next in terms of grain yield stability. Also, Q12, Red Carina and Q22 genotypes had specific adaptation in Karaj and Kashmar, and Giza1 and Q18 genotypes showed high specific adaptation in Urmia. In general, the results of this experiment showed that all quinoa genotypes were compatible with spring cultivation in experimental sites.
\end{abstract}

Key words: Adaptability, AMMI Analysis, Compatibility, Principle components and Quinoa.

\footnotetext{
Received: June, 2020 Accepted February, 2021

1. Assistant Prof., Seed and Plant Improvement Research Institute, Agricultural Research, Education and Extension Organization, Karaj, Iran (Corresponding author) (Email: m-bagheri@areeo.ac.ir)

2. Researcher, Khuzestan Agricultural and Natural Resources Research and Education Center, Agricultural Research Education and Extension Organization, Ahvaz, Iran

3. Assistant Prof., Khorasan-e-Razavi Agricultural and Natural Resources Research and Education Center, Agricultural Research Education and Extension Organization, Mashhad, Iran

4. Researcher, West Azarbaijan Agricultural and Natural Resources Research and Education Center, Agricultural Research Education and Extension Organization, Urmia, Iran

5. Faculty member, Chaharmahal and Bakhtiari Agricultural and Natural Resources Research and Education Center, Agricultural Research Education and Extension Organization, Shahr-e-Kord, Iran

6. Researcher, Seed and Plant Improvement Institute, Agricultural Research Education and Extension Organization, Karaj, Iran
} 